\title{
Desempenho e conversão alimentar de novilhos de corte em capim- tanzânia submetido a duas intensidades de pastejo sob lotação rotativa ${ }^{1}$
}

\section{Gelson dos Santos Difante ${ }^{2^{*}}$, Valéria Pacheco Batista Euclides ${ }^{3}$, Domicio do Nascimento Júnior $^{4}$, Sila Carneiro da Silva ${ }^{5}$, Rodrigo Amorim Barbosa ${ }^{3}$, Roberto Augusto de Almeida Torres Júnior ${ }^{3}$}

${ }^{1}$ Pesquisa financiada pela Fundect e pelo CNPq.

${ }^{2}$ Embrapa Gado de Corte, Rodovia BR 262 km 4, Caixa Postal 154, CEP: 79002-970, Campo Grande, MS.

3 Embrapa Gado de Corte, Campo Grande, MS

${ }^{4}$ Departamento de Zootecnia, UFV. Bolsista CNPq.

${ }^{5}$ Departamento de Zootecnia, USP/ESALQ.

RESUMO - O experimento foi realizado para avaliar o valor nutritivo da forragem, o desempenho e a conversão alimentar de novilhos em pastos de Panicum maximum Jacq. cv. Tanzânia submetidos a duas intensidades de pastejo rotativo (resíduos de 25 e $50 \mathrm{~cm}$ ), associadas a intervalo de pastejo correspondente ao tempo necessário para que o dossel forrageiro interceptasse 95\% da luz incidente durante a rebrotação. O delineamento experimental utilizado foi o de blocos completos casualizados, com duas repetições. Foram avaliados a altura do dossel pré-pastejo, os intervalos de pastejo, o ganho de peso individual, a conversão alimentar, a taxa de lotação e o ganho de peso por unidade de área. Pastos manejados com o resíduo $50 \mathrm{~cm}$ apresentaram maior número de ciclos de pastejo em relação àqueles manejados com resíduo de $25 \mathrm{~cm}$. O maior ganho de peso médio diário foi registrado nos pastos manejados com $50 \mathrm{~cm}$ de resíduo (801 g/dia) em relação àqueles manejados com de $25 \mathrm{~cm}$ de resíduo (664 g/dia). Em contrapartida, a taxa de lotação foi mais alta nos pastos manejados com o resíduo $25 \mathrm{~cm}$, fazendo com que os ganhos de peso por unidade de área fossem 601 e $559 \mathrm{~kg} / \mathrm{ha}$ para os resíduos de 25 e $50 \mathrm{~cm}$, respectivamente. O manejo do pasto visando altura de resíduo de $25 \mathrm{~cm}$ proporciona maiores ganhos de peso por unidade de área e maior uniformidade de produção e o resíduo de $50 \mathrm{~cm}$ promove maior ganho individual e maior número de ciclos de pastejo.

Palavras-chave: bovinos de corte, ganho de peso por unidade de área, ganho médio diário, manejo do pastejo, resíduo pós-pastejo, taxa de lotação

\section{Performance and feed conversion of beef cattle steers on Tanzania guineagrass under two grazing intensities and rotational stocking}

\begin{abstract}
The objective of this experiment was to evaluate the nutritive value, animal performance and feed conversion of beef cattle steers grazing Panicum maximum Jacq. cv. Tanzania pasture subjected to intensities of rotational grazing. Treatments corresponded to two grazing intensities (post-grazing residues of 25 and $50 \mathrm{~cm}$ ) associated with a grazing interval corresponding to the time necessary for a 95\% canopy light interception (LI) condition during regrowth. A randomized complete block design was used, with two replications. The pre-grazing sward height, grazing interval, weight gain, stocking rate and weight gain per unit area were assessed. Pastures managed with $50 \mathrm{~cm}$ residue post-grazing condition resulted in a larger number of grazing cycles than the $25 \mathrm{~cm}$ residue. The highest daily average weight gain was observed in the pastures managed with $50 \mathrm{~cm}$ residue (801 g/.day) compared to those managed with $25 \mathrm{~cm}$ residue (664 g/day). However, the $25 \mathrm{~cm}$ post-grazing condition allowed for higher of stocking rate values, resulting in 601 and $559 \mathrm{~kg}$ weight gain/ha for the 25 and $50 \mathrm{~cm}$ conditions, respectively. Grazing management with a post-grazing residue of $25 \mathrm{~cm}$ result in higher weight gain per unit area and a more stable pattern of animal performance while management with $50 \mathrm{~cm}$ residue result in higher individual performance and a larger number of grazing cycles.
\end{abstract}

Key Words: average daily gain, beef cattle, grazing management, post-grazing residue, stocking rate, weight gain per unit area

Recebido em 14/1/2008 e aprovado em 6/2/2009.

Correspondências devem ser enviadas para: gdifante@ufrnet.br

*Endereço atual: Departamento de Agropecuária - UFRN, Caixa Postal 1524, CEP: 59072-970, Natal, RN 


\section{Introdução}

Em sistemas de produção animal em pasto, o controle da estrutura do dossel, por influenciar o desempenho de plantas e animais, condiciona e determina os padrões de eficiência parcial do sistema, ou seja, o crescimento, a utilização e a conversão da forragem (Hodgson, 1990). Entretanto, a obtenção de níveis máximos de eficiência de cada um desses processos não pode ser alcançada de forma simultânea, indicando que os objetivos de manejo do pastejo devem ser idealizados de forma que a eficiência global do sistema de produção seja otimizada. O aumento da eficiência de transformação da forragem em produto animal é conseguido com o aumento da taxa de lotação sem prejuízos para a produtividade do sistema.

Segundo Da Silva (2004), em virtude do grande potencial de produção das gramíneas tropicais, ocorre subutilização dessas plantas nos sistemas de produção. Essa constatação é agravada pelo fato de, no manejo, de modo geral, não se considerar a importância da eficiência de utilização da forragem produzida. Como não existe preocupação em se ajustar o manejo das pastagens para as situações particulares, os sistemas de produção apresentam baixos índices zootécnicos com reflexos negativos na rentabilidade do empreendimento. Assim, é necessário buscar conhecimentos que possibilitem manejar de forma mais eficiente as pastagens tropicais e delinear estratégias para seu melhor aproveitamento.

Resultados de trabalhos recentes sobre o manejo do pastejo em gramíneas tropicais sugerem que a manutenção de alta produtividade de forragem de boa qualidade só é alcançada com monitoramento capaz de assegurar equilíbrio entre os processos de crescimento, senescência e consumo de forragem. Entre as características das plantas forrageiras mais importantes para a produção animal, destacam-se aquelas que determinam o consumo voluntário de nutrientes digestíveis. Considerando que é o principal fator limitante da produção animal, o consumo restrito (quantidade e, ou, qualidade) de nutrientes só será controlado pelo valor nutritivo se a quantidade disponível de forragem não for limitante (Euclides, 2000). Adicionalmente, sabe-se que não apenas o nível de oferta, mas a forma como a forragem é ofertada aos animais (estrutura do dossel), afeta de forma decisiva o comportamento ingestivo e o consumo (Palhano et al., 2005; Carvalho et al., 2007), e que, em plantas de clima tropical, o componente colmo assume grande importância nos padrões de variação da estrutura do pasto (Da Silva \& Carvalho, 2005; Silva et al. 2007). Sob pastejo rotativo, a interrupção da rebrotação ou do período de descanso quando o dossel intercepta 95\% da luz incidente tem-se mostrado efetiva em controlar o desenvolvimento e acúmulo de colmos, assim como a manutenção de estruturas de pasto favoráveis ao acúmulo de forragem de qualidade (Barbosa et al. 2007; Da Silva \& Nascimento Jr., 2007).

Assim, objetivou-se avaliar o desempenho e a conversão alimentar de novilhos de corte em pastos de Panicum maximum Jacq. cv. Tanzânia manejados em duas intensidades de pastejo rotativo (alturas de resíduo de 25 e $50 \mathrm{~cm}$ ) associadas a uma condição pré-pastejo comum, correspondente a 95\% de interceptação da luz incidente pelo dossel forrageiro.

\section{Material e Métodos}

O experimento foi conduzido no período de setembro de 2004 a maio de 2005 utilizando-se Panicum maximum Jacq. cv. Tanzânia. Os pastos foram formados em janeiro de 1995 e utilizados sob pastejo rotativo até o início da preparação da área para este experimento. O clima na região, segundo a classificação de Köppen, é do tipo tropical chuvoso de savana, subtipo Aw, caracterizado pela distribuição sazonal de chuvas, com um período seco durante os meses mais frios do ano e um período chuvoso durante os meses de verão. Os dados referentes à precipitação pluvial foram registrados no local do experimento, e os dados de umidade relativa do ar e temperaturas (Figura 1) foram registrados em estação meteorológica distante cerca de $800 \mathrm{~m}$ da área experimental.

O solo da área experimental é classificado como Latossolo Vermelho Distrófico (EMBRAPA, 1999), caracterizado por textura argilosa, pH ácido, baixa saturação por bases e alta concentração de alumínio. A fertilidade da

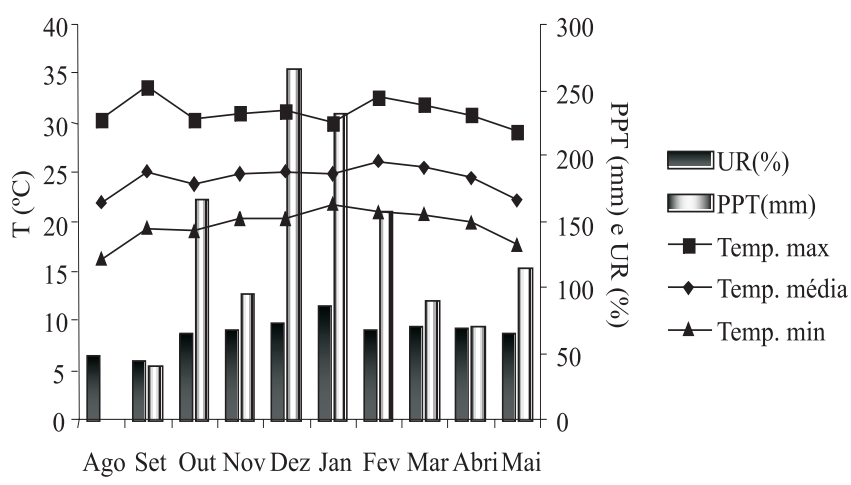

Figura 1- Precipitação pluvial total mensal, umidade relativa do ar, temperaturas máximas, médias e mínimas mensais ocorridas durante o período experimental. 
área foi monitorada e mantida com saturação por bases entre 50 e 70\%, o teor de fósforo entre 8 e $12 \mathrm{mg} / \mathrm{dm}^{3}$ $\left(\mathrm{P}-\right.$ Mehlich $\left.^{1}\right)$ e o teor de potássio, entre 80 e $100 \mathrm{mg} / \mathrm{dm}^{3}$. Nos dias 30/9/2004 e 1/10/2004, foram retiradas 36 amostras de solo por piquete: 12 na profundidade de $0-10 \mathrm{~cm}$; 12 na profundidade de $0-20 \mathrm{~cm}$; e 12 na profundidade de $20-40 \mathrm{~cm}$. A análise química das amostras de solo foi realizada segundo recomendações da EMBRAPA (1997) (Tabela 1).

Com base nos resultados da análise de solo, foram aplicados $1.000 \mathrm{~kg} /$ ha de calcário dolomítico (PRNT 75\%), $800 \mathrm{~kg} / \mathrm{h}$ a de gesso agrícola e $500 \mathrm{~kg} / \mathrm{ha}$ da fórmula 0-20-20. Os piquetes também receberam $150 \mathrm{~kg} / \mathrm{ha}$ de $\mathrm{N}$ na forma de ureia, aplicados de forma parcelada no pós-pastejo de cada piquete. Como os intervalos de pastejo foram variáveis, as quantidades de nitrogênio aplicadas e as datas de aplicação também foram variáveis, porém realizadas de forma que todos os piquetes recebessem a mesma quantidade de nitrogênio até o final do período experimental.

A área experimental de nove hectares foi subdividida em três blocos de três hectares. Cada bloco foi dividido em dois módulos, cada um com seis piquetes de 0,25 ha cada, perfazendo uma área de 1,5 ha por módulo. Dos três blocos, um foi utilizado como área reserva para a manutenção de animais utilizados para realização de ajustes em taxa de lotação quando necessário. Os tratamentos corresponderam a duas intensidades de pastejo rotativo caracterizadas pelas alturas de resíduo pós-pastejo de 25 e $50 \mathrm{~cm}$, ambas associadas a uma condição pré-pastejo comum correspondente ao momento em que o dossel interceptasse 95\% da luz incidente (IL).

O delineamento experimental utilizado foi o de blocos completos casualizados com duas repetições. Cada repetição compreendia um módulo de seis piquetes, de maneira que os animais alocados a cada uma das repetições permanecessem sempre no mesmo tratamento, caracterizando uma unidade autocontida de manejo (total de 24 piquete, com quatro módulos de seis piquetes correspondentes a dois tratamentos e duas repetições).

O método de pastejo empregado foi o de lotação intermitente (rotativa), com taxa de lotação variável. Antes do início do experimento, em novembro de 2004, foram feitas roçadas de uniformização dos pastos após os primeiros pastejos da primavera como forma de assegurar que as alturas de resíduo planejadas fossem precisamente geradas. Essas roçadas foram feitas semanalmente em um piquete por módulo de forma a assegurar um gradiente de rebrotação entre os piquetes dentro de cada módulo. Esse procedimento foi adotado até que todos os piquetes do módulo foram roçados e só foi realizado por ocasião do início do experimento. O período de avaliação começou em 13/12/2004 e terminou em 18/5/2005, totalizando 156 dias.

Foram utilizados 60 novilhos da raça Nelore, oriundos do plantel da EMBRAPA Gado de Corte, com aproximadamente 12 meses de idade e peso médio inicial de $221 \mathrm{~kg}$. Desses, foram selecionados 24 animais-teste com peso médio inicial de $232 \mathrm{~kg}$, os quais foram distribuídos em quatro grupos de seis animais, que foram alocados de forma aleatória às unidades experimentais. Os 36 animais restantes foram mantidos no bloco reserva e utilizados para a realização dos ajustes em taxa de lotação do experimento sempre que necessário. Os animais-teste foram pesados no final de cada ciclo de pastejo (correspondente ao número de dias para executar o pastejo nos seis piquetes de cada módulo experimental) e os animais-reguladores mensalmente para acompanhamento do ganho de peso e cálculo dos ajustes na taxa de lotação. As pesagens foram realizadas após jejum de alimento e água de 16 horas.

Os ajustes na taxa de lotação foram feitos de acordo com a evolução da interceptação de luz pelo dossel nos piquetes seguintes na sequência de pastejo de cada módulo de avaliação. Esse procedimento teve como objetivo obter o resíduo determinado para o tratamento no momento em que o próximo piquete do módulo a ser pastejado atingisse a meta de pré-pastejo estipulada de 95\% de IL. A taxa de lotação por ciclo de pastejo (animais de $300 \mathrm{~kg} / \mathrm{ha}$ ) foi calculada como o produto do peso médio dos animaisteste e dos animais-reguladores pelo número de dias que permaneceram no módulo, de acordo com Petersen \& Lucas Jr. (1968).

O ganho de peso médio diário (g/animal.dia) foi calculado pela diferença do peso dos animais-teste, no início e final de cada ciclo de pastejo, dividida pelo número de dias do ciclo. O ganho de peso animal por hectare ( $\mathrm{kg} /$ ha de peso animal produzido) foi obtido multiplicando-se o ganho médio diário dos animais-teste pelo número de animais mantidos por hectare em cada ciclo de pastejo.

Tabela 1 - Características químicas das amostras de solo da área experimental nas camadas de 0-10 cm, 0-20 cm e 20-40 cm

\begin{tabular}{|c|c|c|c|c|c|c|c|c|c|c|}
\hline \multirow{2}{*}{$\begin{array}{c}\text { Camada } \\
(\mathrm{cm}) \\
\end{array}$} & $\mathrm{P}$ & MO & $\mathrm{pH}$ & K & $\mathrm{Ca}$ & $\mathrm{Mg}$ & $\mathrm{H}+\mathrm{Al}$ & $\mathrm{S}$ & $\mathrm{T}$ & $\mathrm{V}$ \\
\hline & $\mathrm{mg} / \mathrm{dm}^{3}$ & $\%$ & $\mathrm{CaCl}_{2}$ & $\mathrm{mg} / \mathrm{dm}^{3}$ & \multicolumn{5}{|c|}{$\mathrm{cmol}_{\mathrm{c}} / \mathrm{dm}^{3}$} & $\%$ \\
\hline $0-10$ & 3,74 & 5,00 & 5,31 & 162,48 & 2,58 & 1,85 & 4,50 & 4,84 & 9,09 & 53,3 \\
\hline $0-20$ & 2,08 & 5,41 & 5,01 & 128,38 & 1,84 & 1,23 & 5,32 & 3,39 & 8,71 & 41,0 \\
\hline $20-40$ & 0,78 & 2,99 & 4,70 & 39,40 & 0,78 & 0,48 & 3,27 & 1,36 & 4,88 & 28,0 \\
\hline
\end{tabular}


O ganho de peso total foi o somatório dos ganhos de peso por hectare de todos os ciclos de pastejo para cada intensidade de pastejo. Já a conversão alimentar (kg MS/ $\mathrm{kg}$ ganho de peso) foi calculada como o quociente entre o consumo médio individual de forragem (Difante et al., 2009a) e o ganho médio individual durante o ciclo de pastejo em que foi estimado o consumo.

No início do experimento, os animais foram tratados com vermífugo de amplo espectro e, durante o período experimental, foram tratados com ectocida "pour-on", conforme a necessidade de controle de carrapatos e moscado-chifre. Todos os piquetes foram providos de cochos plásticos e bebedouros de concreto com acesso livre para os animais e constantemente foram supervisionados para garantir o fornecimento de sal mineral da fórmula (EMBRAPA Gado de Corte) e água potável durante todo período experimental.

O monitoramento da interceptação de luz pelo dossel foi realizado no início de cada período de rebrotação (na condição pós-pastejo) e semanalmente até que os níveis de interceptação de luz estivessem próximos da meta de 95\%, condição em que passavam a ser realizadas a cada dois ou três dias até que a meta fosse atingida. As medições foram realizadas utilizando-se o aparelho analisador de dossel AccuPAR Linear PAR/LAI ceptometer, Model PAR - 80 (DECAGON Devices ${ }^{\circledR}$ ), com o qual foram realizadas leituras em 18 estações por piquete, divididas em três linhas com seis estações cada uma. Em cada estação, foram realizadas uma leitura acima do dossel forrageiro e cinco no nível do solo com o sensor ótico posicionado no ponto médio da distância entre duas touceiras. No total foram tomadas por piquete 18 leituras acima do dossel e 90 leituras no nível do solo por avaliação.

A altura do dossel foi medida em 40 pontos por piquete, divididos em cinco linhas de oito pontos escolhidos de forma aleatória, utilizando-se uma régua de um metro. As leituras foram feitas no plano de curvatura das folhas superiores em torno da régua e realizadas no mesmo dia das avaliações e monitoramento de interceptação de luz.

A massa de forragem pré e pós-pastejo foi estimada mediante o corte de seis áreas representativas dos piquetes (avaliação visual de altura e massa) em três dos seis piquetes de cada módulo. Para isso foram utilizadas duas armações metálicas de $1 \mathrm{~m}^{2}$. Para avaliação do teor de matéria seca da forragem, retirou-se uma subamostra correspondendo a aproximadamente $50 \%$ da original (peso verde conhecido), a qual foi acondicionada em saco de papel e seca em estufa de ventilação forçada de ar a $65{ }^{\circ} \mathrm{C}$ até peso constante.
Para avaliação da composição morfológica da massa de forragem, foram retiradas duas subamostras representativas das amostras colhidas para determinação da massa de forragem. Essas subamostras foram separadas manualmente nas frações folha (lâmina foliar), colmo (colmos + bainhas) e material morto e os componentes foram pesados e secos em estufa de circulação forçada de ar a $65^{\circ} \mathrm{C}$ até peso constante. Os valores de massa de forragem foram convertidos para $\mathrm{kg} / \mathrm{ha}$ de matéria seca e os componentes morfológicos expressos em porcentagem (\%) da massa de forragem.

As amostras dos componentes morfológicos (folha, colmo e material morto) foram moídas e posteriormente analisadas utilizando-se o sistema de Espectrofotometria de Refletância no infravermelho proximal (NIRS), de acordo com os procedimentos de Merten et al. (1985), para estimativa dos teores de matéria orgânica (MO), proteína bruta (PB), fibra em detergente neutro (FDN), digestibilidade in vitro da matéria orgânica (DIVMO) e lignina em detergente ácido (LDA).

$\mathrm{O}$ acúmulo de forragem foi calculado pela diferença entre as massas de forragem no pré-pastejo atual e no póspastejo anterior de cada piquete. As taxas de acúmulo de forragem (kg de MS/ha.dia) foram calculadas dividindo-se o acúmulo de forragem pelo número de dias de rebrotação.

A altura do dossel e a interceptação luminosa, que caracterizam a estrutura do dossel durante o período experimental, são apresentadas utilizando-se estatística descritiva (médias). Para a análise estatística dos dados, foi utilizado um modelo contendo os efeitos fixos de resíduo, bloco e animais dentro de tratamento, além das interações simples entre eles. As análises foram realizadas pelo método dos quadrados mínimos, utilizando-se o procedimento General Linear Model disponível no programa computacional SAS (SAS, 1993).

\section{Resultados e Discussão}

Os intervalos de pastejo foram afetados $(\mathrm{P}=0,0547)$ pelas alturas de resíduo pós-pastejo (Figura 2). Pastos manejados com resíduo de $50 \mathrm{~cm}$ apresentaram menores intervalos de pastejo, com média de 33 dias, enquanto aqueles manejados com resíduo de $25 \mathrm{~cm}$ apresentaram maiores intervalos de pastejo, com média de 50 dias, o que resultou em menor número de ciclos de pastejo ao final do experimento.

O tempo de recuperação do pasto após desfolhação também foi influenciado pelos níveis de precipitação pluvial durante o período experimental (Figura 1). Nos meses de dezembro, janeiro e fevereiro, em que houve 


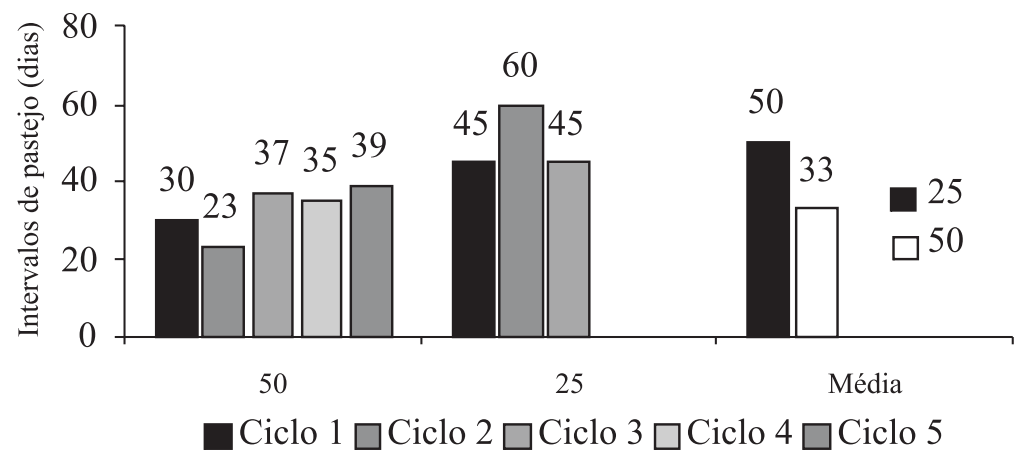

Figura 2 - Intervalo de pastejo (dias) de pastos de capim-tanzânia submetidos a intensidades de pastejo rotativo de janeiro a maio de 2005.

concentração de chuvas, foram verificados os menores intervalos de pastejos.

De modo geral, a meta de interceptação de luz pré-pastejo e alturas de resíduo pós-pastejo foram mantidas adequadamente durante todo o período experimental (Tabela 2). A massa de forragem pré-pastejo não diferiu entre as alturas de resíduo testadas $(\mathrm{P}=0,0635)$. O mesmo nível de interceptação de luz utilizado como meta para entrada dos animais nos piquetes pode explicar a semelhança entre as massas de forragem pré-pastejo.

Na condição pós-pastejo, a massa de forragem variou com a altura de resíduo utilizada $(\mathrm{P}=0,0006)$ e o resíduo de $25 \mathrm{~cm}$ foi o que resultou em menor massa de forragem. A maior taxa de acúmulo foi observada quando o pasto foi manejado a $50 \mathrm{~cm}$ de altura de resíduo $(\mathrm{P}=0,0951)$, porém, mesmo com as maiores taxas, não houve diferença na massa de forragem pré-pastejo, uma vez que, quanto maiores as taxas de acúmulo de forragem dos pastos, mais curtos foram os intervalos de pastejo (33 dias, Figura 2). O maior intervalo de pastejo para o resíduo de $25 \mathrm{~cm}$ (50 dias, Figura 2) compensou a menor taxa de acúmulo em relação ao resíduo de $50 \mathrm{~cm}$.
As proporções de folha na massa de forragem prépastejo não diferiram ( $\mathrm{P}=0,0689)$, assim como as de material morto $(\mathrm{P}=0,3366)$, entre as alturas de resíduo testadas, porém a proporção de colmo foi maior para os pastos manejados com resíduo pós-pastejo de $50 \mathrm{~cm}(\mathrm{P}=0,0108)$. Esse maior acúmulo de colmo no resíduo pós-pastejo mais alto indica que, apesar desse manejo favorecer o desempenho individual dos animais, essa condição de manejo configura menor controle da estrutura do dossel, o que pode prejudicar o acúmulo e o valor nutritivo da forragem produzida no médio e longo prazo.

Não houve diferença no valor nutritivo da massa de forragem pré-pastejo (Tabela 3), estratificada em componentes morfológicos ( $\mathrm{P}>0,05)$, o que pode ser explicado pelo fato de que uma única condição pré-pastejo foi utilizada para o manejo dos pastos (95\% de IL). Os animais mantidos nos pastos manejados com $25 \mathrm{~cm}$ de altura de resíduo devem ter consumido maior quantidade de colmo e material morto, uma vez que esses componentes se encontravam em maiores proporções no estrato localizado entre 25 e $50 \mathrm{~cm}$ de altura, pois o estrato localizado acima de $50 \mathrm{~cm}$ era composto praticamente apenas por folhas (Difante et al., 2009b).

Tabela 2 - Interceptação luminosa (\%), altura do dossel pré e pós-pastejo (cm), massa de forragem pré e pós-pastejo (kg/ha de MS), taxa de acúmulo de MS (kg/ha.dia) e composição morfológica da massa de forragem pré-pastejo (\%) de pastos de capim-tanzânia submetidos a intensidades de pastejo rotativo de janeiro a maio de 2005

\begin{tabular}{|c|c|c|}
\hline \multirow[t]{2}{*}{ Variável } & \multicolumn{2}{|c|}{ Altura de resíduo (cm) } \\
\hline & 25 & 50 \\
\hline Interceptação luminosa (\%) & 95,0 & 95,8 \\
\hline Altura do dossel pré-pastejo (cm) & 65,0 & 68,4 \\
\hline Altura do dossel pós-pastejo (cm) & 26,5 & 47,8 \\
\hline Massa de forragem pré-pastejo (kg/ha de MS) & $7130 \mathrm{a}(3,82)$ & $8600 \mathrm{a}(3,21)$ \\
\hline Massa de forragem pós-pastejo (kg/ha de MS) & $3810 \mathrm{~b}(372,30)$ & $5080 \mathrm{a}(329,20)$ \\
\hline Taxa de acúmulo de MS (kg/ha.dia de MS) & $90,6 b(8,60)$ & $164,9 \mathrm{a}(7,20)$ \\
\hline 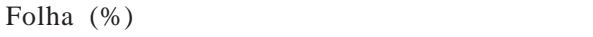 & $61,7 a(0,17)$ & $59,6 a(0,14)$ \\
\hline Colmo (\%) & $13,4 b(0,03)$ & $15,9 \mathrm{a}(0,03)$ \\
\hline Material morto (\%) & $25,0 \mathrm{a}(0,20)$ & $24,5 a(0,17)$ \\
\hline
\end{tabular}

Médias seguidas de mesma letra na linha não diferem $(\mathrm{P}>0,05)$ pelo teste Tukey.

Valores entre parênteses representam os erros-padrão das médias (EPM). 
Tabela 3 - Teores de proteína bruta, fibra insolúvel em detergente neutro, lignina insolúvel em detergente ácido, e digestibilidade in vitro da matéria orgânica (DIVMO, \%) dos componentes morfológicos da massa de forragem pré-pastejo de pastos de capim-tanzânia submetidos a intensidades de pastejo rotativo de janeiro a maio de 2005

\begin{tabular}{lccc}
\hline Variável & Folha & Colmo & Material morto \\
\hline Proteína bruta (\%) & $10,5(0,72)$ & $6,1(0,45)$ & $5,6(0,31)$ \\
Fibra em detergente neutro (\%) & $76,6(0,39)$ & $78,8(0,93)$ & $78,5(0,37)$ \\
DIVMO (\%) & $57,2(1,98)$ & $52,5(0,95)$ & $32,0(0,64)$ \\
Lignina em detergente ácido (\%) & $3,3(0,06)$ & $4,5(0,12)$ & $5,5(0,01)$ \\
\hline
\end{tabular}

Valores entre parênteses representam os erros-padrão das médias (EPM).

Considerando a uniformidade do lote de animais utilizados no experimento quanto ao seu potencial para ganho de peso, pode-se inferir que a produção animal mensurada em cada manejo testado foi reflexo da oferta de forragem, da forma como essa forragem se encontrava distribuída ao longo do perfil do dossel forrageiro, do valor nutritivo da forragem consumida e da habilidade dos animais em colher a forragem ofertada, resultando em maior ou menor consumo e em diferenças no ganho de peso.

O maior ganho médio diário foi observado nos animais mantidos nos pastos manejados com $50 \mathrm{~cm}$ de altura de resíduo ( $\mathrm{P}=0,0013)$ (Tabela 4 ) e foi $20,7 \%$ superior àquele dos animais mantidos nos pastos manejados com $25 \mathrm{~cm}$ altura de resíduo. Entretanto, os pastos manejados com a altura de resíduo $25 \mathrm{~cm}$ mantiveram 1,2 novilho de $300 \mathrm{~kg}$ a mais por hectare que pastos manejados com a altura de resíduo $50 \mathrm{~cm}(\mathrm{P}=0,0647)$.

O maior ganho de peso dos animais submetidos aos pastos manejados com altura de resíduo de $50 \mathrm{~cm}$ pode ser justificado pelo maior consumo diário de forragem (10\% superior) em relação aos animais submetidos aos pastos manejados com altura de resíduo de $25 \mathrm{~cm}$ (Difante et al., 2009a), uma vez que a digestibilidade da forragem consumida pelos animais foi semelhante em ambos os pastos. Carvalho et al. (2001) ressaltam que, quando os animais passam a ter que consumir os estratos mais baixos do pasto, a massa do bocado torna-se menor, fruto da diminuição da altura das plantas, que acarreta menor profundidade do bocado, e da diminuição da área do bocado, em resposta ao aumento da densidade da forragem, o que pode limitar o consumo de forragem e o desempenho dos animais, fato que pode ter ocorrido quando o pasto foi manejado com altura de resíduo de $25 \mathrm{~cm}$.

Minson (1990) relatou que, quando o animal está acostumado a consumir folhas, continua procurando por elas, mesmo quando a proporção de folhas presentes no dossel forrageiro é baixa, fato observado também por Brâncio et al. (2003). Esse comportamento pode ter contribuído com o menor consumo, em virtude da rejeição da forragem com alta proporção de colmo e material morto.

A conversão alimentar, por sua vez, diferiu entre as alturas de resíduo pós-pastejo avaliadas. Animais mantidos nos pastos manejados com resíduo de $50 \mathrm{~cm}$ apresentaram melhor conversão alimentar em comparação àqueles mantidos nos pastos manejados com resíduo de $25 \mathrm{~cm}$ ( $\mathrm{P}=0,06$ ), com médias de 8,9 e 10,3 kg de MS/kg de ganho, respectivamente. A melhor conversão da forragem ingerida em produto animal nos pastos manejados a $50 \mathrm{~cm}$ de resíduo foi resultado, provavelmente, do maior consumo diário de forragem (cerca de 10\%), muito embora essa diferença não tenha sido significativa (Difante et al., 2009a), e da maior proporção de folhas no estrato acima de $50 \mathrm{~cm}$, componente morfológico de maior valor nutritivo.

Em contrapartida, pastos manejados com altura de resíduo $25 \mathrm{~cm}$ apresentaram maior taxa de lotação que pastos manejados com altura de resíduo $50 \mathrm{~cm}$, consequência da maior intensidade de pastejo e da remoção de forragem ocasionadas por esse manejo, fazendo com que os animais permanecessem nos piquetes até consumir a forragem presente nos estratos acima de $25 \mathrm{~cm}$. Embora o intervalo de pastejo para o pasto com altura de resíduo de $25 \mathrm{~cm}$ tenha sido maior que naquele com altura de resíduo de $50 \mathrm{~cm}$

Tabela 4 - Ganho de peso médio diário, conversão alimentar e taxa de lotação em pastos de capim-tanzânia submetidos a intensidades de pastejo rotativo de janeiro a maio de 2005

\begin{tabular}{lcc}
\hline Variável & \multicolumn{2}{c}{ Altura de resíduo (cm) } \\
\cline { 2 - 3 } & 25 & 50 \\
Ganho médio diário (g/dia) & $664 \mathrm{~b}(0,03)$ & $801 \mathrm{a}(0,03)$ \\
Conversão alimentar (kg MS consumida/kg ganho de peso) & $10,3 \mathrm{a}(0,48)$ & $8,9 \mathrm{~b}(0,48)$ \\
Taxa de lotação (animais de 300 kg/ha) & $6,1 \mathrm{a}(0,22)$ & $9,6 \mathrm{~b}(0,22)$ \\
\hline
\end{tabular}


(Figura 2), a maior oferta de forragem desse pasto ainda permitiu a manutenção de uma taxa de lotação mais elevada.

De modo geral, a facilidade para o ajuste em taxa de lotação nos pastos manejados com a altura de resíduo $25 \mathrm{~cm}$ foi maior que nos pastos manejados com altura de resíduo $50 \mathrm{~cm}$. Isso porque o período médio de ocupação dos piquetes manejados com altura de resíduo $25 \mathrm{~cm}$ foi maior ( 8,3 vs 5,5 dias para as alturas de resíduo 25 e $50 \mathrm{~cm}$, respectivamente), o que propiciou maior facilidade de planejamento e permitiu maior flexibilidade na movimentação dos animais de um piquete para o outro, assegurando que a meta de $95 \%$ de interceptação de luz pré-pastejo fosse mantida. Esse fato, associado à menor variação em composição morfológica, especialmente do resíduo, sugere que a altura de resíduo $25 \mathrm{~cm}$ pode ser uma alternativa mais interessante de manejo em se tratando de períodos longos de utilização e considerando a manutenção e o controle da estrutura dos pastos e a eficiência de pastejo.

Os animais mantidos nos pastos manejados com resíduo de $25 \mathrm{~cm}$ de altura apresentaram menor variação no desempenho individual (Figura 3) e na taxa de lotação utilizada ao longo de todo o período experimental em relação àqueles mantidos nos pastos manejados com resíduo de $50 \mathrm{~cm}$ de altura, fato desejável em termos de estratégia de manejo. Por outro lado, a altura de resíduo mais baixa implica alta eficiência de pastejo em relação à altura de resíduo mais alta (90 vs 50\% para as alturas de resíduo 25 e $50 \mathrm{~cm}$, respectivamente) (Difante et al., 2009a), aumentando a importância relativa do nível de fertilidade basal do solo e/ou da utilização de práticas de adubação de manutenção ou reposição de nutrientes.

Nos pastos manejados com altura de resíduo de $50 \mathrm{~cm}$, os menores valores de ganho médio diário foram registrados no segundo ciclo de pastejo, ocorrido durante o mês de fevereiro, que, apesar de ter precipitação de 156 mm (Figura 1), ocorreu apenas durante os oito primeiros dias do mês. Após esse período, só voltou a chover no dia 3/3/2005 e no último período de avaliação, durante os meses de abril e maio, quando apenas $30,4 \mathrm{~mm}$ de precipitação ocorreram durante o ciclo de pastejo. Essa oscilação nos valores de GMD registrada nos animais mantidos nos pastos manejados com altura de resíduo de $50 \mathrm{~cm}$ pode ter sido ocasionada pela maior frequência nas pesagens dos animais, resultado do menor intervalo de pastejo, que resultou em ciclos de pastejo mais curtos. Esse fato pode ter permitido que os efeitos das condições adversas de clima dentro de ciclo de pastejo fossem detectados mais facilmente quando os pastos foram manejados com $50 \mathrm{~cm}$ de altura de resíduo. Por outro lado, nessa condição de

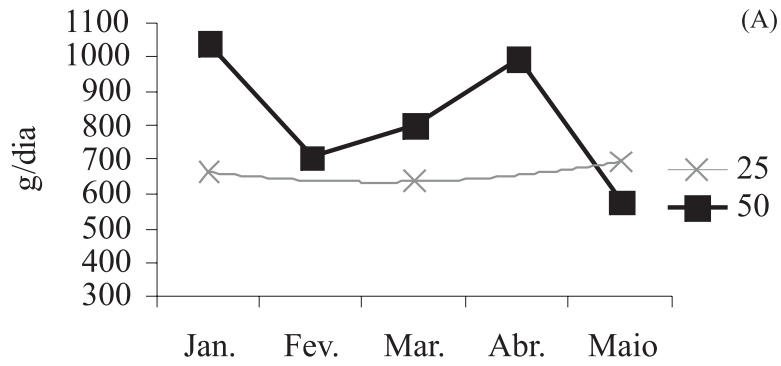

(A)

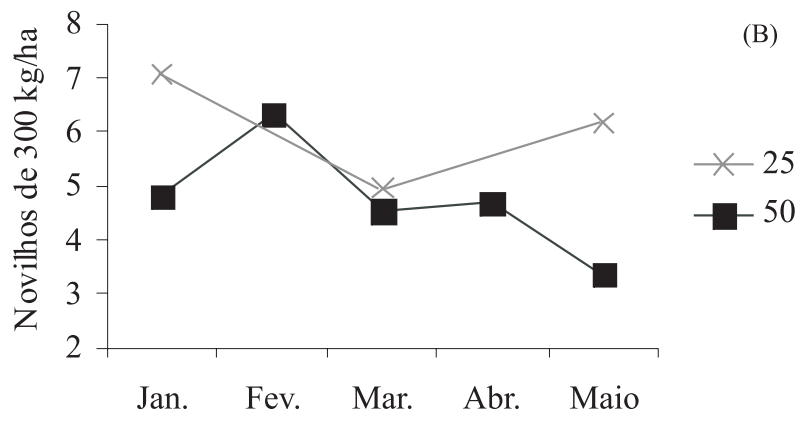

Figura 3 - Ganho de peso médio diário e taxa de lotação em pastos de capim-tanzânia submetidos a intensidades de pastejo rotativo de janeiro a maio de 2005 .

manejo, houve maior variação na composição morfológica (especialmente colmo e material morto) do dossel, particularmente próximo à altura de $50 \mathrm{~cm}$ em relação àquela correspondente à altura de resíduo $25 \mathrm{~cm}$. Entretanto, neste último caso, as variações podem ter sido mascaradas dentro do ciclo de pastejo, que foram mais longos que aqueles de pastos manejados com $50 \mathrm{~cm}$ de altura de resíduo ( 45 a 60 dias vs 23 a 39 dias para as alturas de resíduo 25 e $50 \mathrm{~cm}$, respectivamente) (Figura 2).

O ganho de peso por unidade de área depende do desempenho individual e da taxa de lotação empregada. Quando comparados (Figura 4), os pastos manejados com altura de resíduo de $25 \mathrm{~cm}$ apresentaram padrão de produção relativamente estável durante todos os períodos avaliados, além de proporcionar ganho de peso superiores aos obtidos em pastos manejados com altura de resíduo de $50 \mathrm{~cm}$ (601 vs $559 \mathrm{~kg} / \mathrm{h}$ a para os resíduos de 25 e $50 \mathrm{~cm}$, respectivamente), que, por sua vez, apresentaram menor número de ciclos de pastejo (Figura 2) e maior desempenho individual (Tabela 4).

O menor ganho de peso registrado no último ciclo de pastejo nos pastos manejados com resíduo de $50 \mathrm{~cm}$ foi consequência do menor GMD e da menor taxa de lotação observados nesse período (Figura 3), que podem ser explicados pela menor eficiência de pastejo observada nesses pastos. Apenas $50 \%$ da forragem produzida foi removida pelos animais no resíduo de $50 \mathrm{~cm}$, enquanto, nos 
pastos manejados com resíduo de $25 \mathrm{~cm}, 90 \%$ da forragem produzida foi efetivamente colhida, o que justifica a maior taxa de lotação, mesmo com menores taxas de acúmulo de MS (Tabela 2). Essa menor eficiência de pastejo também pode ter favorecido o acúmulo de colmo e material morto nesse último ciclo de pastejo (Difante et al., 2009b), época em que o pasto entra em estágio reprodutivo, aliado à redução da qualidade das lâminas foliares remanescentes, o que pode ter diminuído a qualidade da dieta consumida e o ganho médio diário dos animais.

Esse padrão de respostas indica que a decisão pela altura de resíduo de 25 ou $50 \mathrm{~cm}$ depende do objetivo geral e das metas estipuladas para determinado sistema de produção. Existem momentos em que o desempenho individual deve ser aumentado, como, por exemplo, na terminação de bovinos. Nesse caso, seria interessante a altura de resíduo de $50 \mathrm{~cm}$. Por outro lado, quando o objetivo é manter maior número de animais no processo produtivo, por exemplo, na fase de recria, ou quando o preço da arroba está baixo, seria interessante a altura de resíduo de $25 \mathrm{~cm}$, que, mesmo apresentando ciclos de pastejo mais longos, proporcionou maior ganho de peso por unidade de área.

Por outro lado, pode haver situações em que seja interessante a associação das duas alturas de resíduo avaliadas, utilizando-se a época de maior acúmulo de forragem para aumentar o ganho individual mantendo-se maior oferta de forragem por meio de um resíduo mais alto e, nas épocas de menor acúmulo de forragem, utilizando-se resíduo mais baixo, de forma a manter maior número de animais na propriedade por meio de maior taxa de lotação, otimizando a eficiência de pastejo e o aproveitamento da forragem produzida.

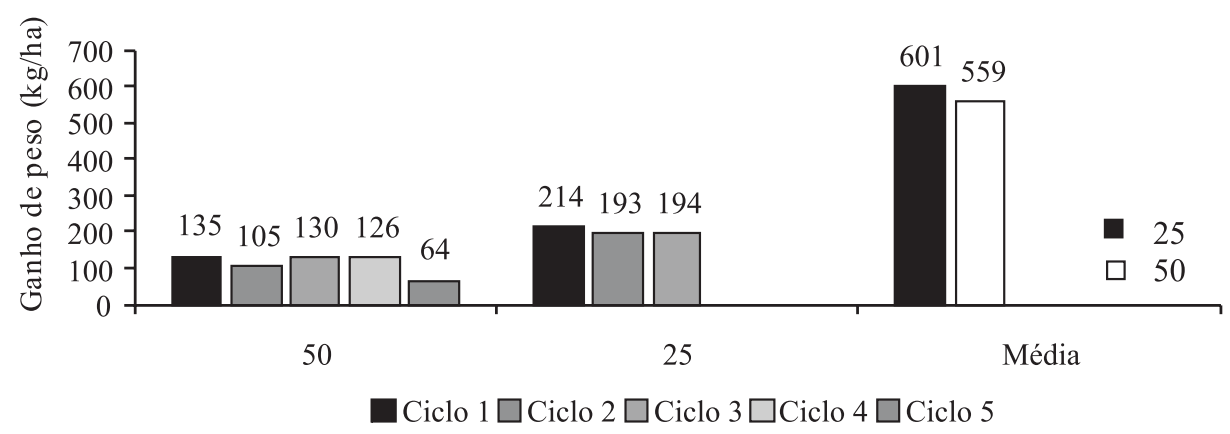

Figura 4 - Ganho de peso por unidade de área (kg/ha) em pastos de capim-tanzânia submetidos a intensidades de pastejo rotativo de janeiro a maio de 2005.

\section{Conclusões}

A altura de resíduo $25 \mathrm{~cm}$ proporciona maiores ganhos por unidade de área e maior uniformidade de produção, enquanto a altura de resíduo $50 \mathrm{~cm}$ promove maior ganho individual e maior número de ciclos de pastejo, portanto, a definição das metas de altura de resíduo do pasto depende do nível de desempenho e produtividade animal almejados, além dos objetivos no sistema de produção.

\section{Agradecimentos}

À Universidade Federal de Viçosa, pela oportunidade do treinamento em nível de Doutorado; ao Conselho Nacional de Desenvolvimento Científico e Tecnológico CNPq, pela concessão de bolsa de estudo ao primeiro autor; à Empresa Brasileira de Pesquisa Agropecuária - Embrapa Gado de Corte, pela disponibilização da área e animais para a execução do experimento; à Fundação de Apoio ao Desenvolvimento do Ensino, Ciência e Tecnologia do Estado de Mato Grosso do Sul - Fundect, pelo financiamento parcial do projeto.

\section{Referências}

BARBOSA, R.A.; NASCIMENTO JR., D; EUCLIDES, V.P.B. et al. Capim-tanzânia submetido a combinações entre intensidade e freqüência de pastejo. Pesquisa Agropecuária Brasileira, v.42, n.3, p.329-340, 2007.

BRÂNCIO, P.A.; NASCIMENTO JR., D.; EUCLIDES, V.P.B. et al. Avaliação de três cultivares de Panicum maximum Jacq. sob pastejo: composição da dieta, consumo de matéria seca e ganho de peso animal. Revista Brasileira de Zootecnia, v.32, n.5, p.1037-1044, 2003.

CARVALHO, P.C.F.; RIBEIRO FILHO, H.M.N.; POLI, C.H.E.C. et al. Importância da estrutura da pastagem na ingestão e seleção de dietas pelo animal em pastejo. In: REUNIÃO ANUAL DA SOCIEDADE BRASILEIRA DE ZOOTECNIA, 38., 2001, Piracicaba. Anais... Piracicaba: Fundação de Estudos Agrários Luiz de Queiroz, 2001. p.853-871. 
CARVALHO, P.F.; CARVALHO, J.K.; TRINDADE, S.M. et al. Consumo de forragens por bovinos em pastejo. In: PEDREIRA, C.G.S.; MOURA, J.C.; DA SILVA, S. et al. (Eds.) SIMPOSIO SOBRE MANEJO DA PASTAGEM. 24., 2007, Piracicaba. Anais... Piracicaba: Fundação de Estudos Agrários Luiz de Queiroz, 2007. p.177-218.

DA SILVA, S.C. Understanding the dynamics of herbage accumulation in tropical grass species: the basis for planning efficient grazing management practices. In: INTERNATIONAL SYMPOSIUM ON GRASSLAND ECOPHYSIOLOGY AND GRAZING ECOLOGY, 2., 2004, Curitiba. Proceedings... Curitiba: 2004. (CD-ROM).

DA SILVA, S.C.; CARVALHO, P.C.F. Foraging behaviour and intake in the favourable tropics/sub-tropics. In: McGILLOWAY, D.A. (Ed.) Grassland: a global resource. Dublin: Wageningen Academic Publishers, 2005. p.81-95.

DA SILVA, S.C.; NASCIMENTO JR., D. Avanços na pesquisa com plantas forrageiras tropicais em pastagens: características morfofisiológicas e manejo do pastejo. Revista Brasileira de Zootecnia, v.36, n.4, p.121-138, 2007 (suplemento especial). DIFANTE, G.S; EUCLIDES, V.P.B.; NASCIMENTO JR., D. et al. Ingestive behaviour, herbage intake and grazing efficiency of beef cattle steers on Tanzania guineagrass subjected to rotational stocking managements. Revista Brasileira de Zootecnia, v.38, n.6, p.1001-1008, 2009a.

DIFANTE, G.S; NASCIMENTO JR., D.; EUCLIDES, V.P.B. et al. Sward structure and nutritive value of tanzânia guineagrass subjected to rotational stocking managements. Revista Brasileira de Zootecnia, v.38, n.1, p.9-19, 2009b.
EMPRESA BRASILEIRA DE PESQUISA E AGROPECUÁRIA EMBRAPA - Centro Nacional de Pesquisa de Solos. Manual de métodos de análise química do solo. 2.ed. Brasília: 1997. 212p.

EMPRESA BRASILEIRA DE PESQUISA AGROPECUÁRIA EMBRAPA. Centro Nacional de Pesquisa de Solos. Sistema brasileiro de classificação de solos. Brasília: Embrapa Produção de Informação; Rio de Janeiro: Embrapa Solos, 1999. 412p.

EUCLIDES, V.P.B. Alternativas para a intensificação da carne bovina em pastagem. Campo Grande: EMBRAPA-Gado de Corte, 2000. 65p.

HODGSON, J. Grazing management: science into practice. New York: John Wiley \& Sons, 1990. 203p.

MERTEN, G.C.; SHENK, J.S.; BARTON, F.E. Near infrared reflectance spectroscopy (NIRS), analysis of forage quality. Washington: USDA, ARS, 1985. 110p. (Agriculture Handbook, 643).

MINSON, D.J. Forage in ruminant nutrition. San Diego: Academic Press, 1990. 483p.

PALHANO, A.L.; CARVALHO, P.C.F.; DITTRICH, J.R. et al. Estrutura da pastagem e padrões de desfolhação em capimmombaça em diferentes alturas do dossel forrageiro. Revista Brasileira de Zootecnia, v.34, n.6, p.1860-1870, 2005.

PETERSEN, R.G.; LUCAS JR., H.L. Computing methods for the evaluation of pastures by means of animal response. Agronomy Journal, v.60, p.682-687, 1968.

SILVA, R.G.; CÂNDIDO, M.J.D.; NEIVA, J.N.M. et al. Características estruturais do dossel de pastagens de capim-tanzânia mantidas sob três períodos de descanso com ovinos. Revista Brasileira de Zootecnia, v.36, n.5, p.1255-1265, 2007.

STATISTICAL ANALYSIS SYSTEM - SAS. User's guide statistics. v.6, 4.ed. Cary: SAS Institute, v.1,2, 1993. 917p. 